\title{
Diagnostic equivalency of mobile CTG devices and remote analysis to conventional on-site nonstress test
}

\author{
Renata Pilarczyk ${ }^{1, A-D}$, Mateusz Strózik ${ }^{2,1, A-D}$, Lidia Hirnle $e^{1, E, F}$ \\ ${ }^{1} 1^{\text {st }}$ Department and Clinic of Gynecology and Obstetrics, Wroclaw Medical University, Poland \\ 2 Division of Histology and Embryology, Department of Human Morphology and Embryology, Wroclaw Medical University, Poland \\ A - research concept and design; $B$ - collection and/or assembly of data; $C$ - data analysis and interpretation; \\ $D$ - writing the article; $E$ - critical revision of the article; $F$ - final approval of the article
}

\section{Mateusz Strózik \\ E-mail: juriaa@gmail.com \\ Funding sources \\ None declared \\ Conflict of interest \\ None declared}

Address for correspondence

Received on February 28, 2019

Reviewed on June 15, 2019

Accepted on August 18, 2019

Published online on January 21, 2020

Cite as

Pilarczyk R, Strózik M, Hirnle L. Diagnostic equivalency of mobile (TG devices and remote analysis to conventional on-site nonstress test. Adv Clin Exp Med. 2020;29(1):33-44. doi:10.17219/acem/111812

DOI

10.17219/acem/111812

\section{Copyright}

Copyright by Author(s)

This is an article distributed under the terms of the

Creative Commons Attribution 3.0 Unported (CC BY 3.0)

(https://creativecommons.org/licenses/by/3.0/)

\begin{abstract}
Background. Remote pregnancy monitoring is one of the most promising applications of telemedicine; however, the diagnostic value of self-examination using mobile cardiotocography (CTG) devices and remote analysis of the subsequent results has never been properly studied.
\end{abstract}

Objectives. The study aimed to compare the diagnostic usefulness of CTG self-examination using a mobile device to examination performed by a medical professional using a stationary device; and to evaluate the quality of CTG analysis performed remotely.

Material and methods. Eighty-two pairs of (TG recordings were collected; each pair consisted of a single recording from an examination performed by a midwife using a stationary device, and another recording from an unassisted patient self-examination using a mobile device. Recordings were performed with a maximum time interval of $30 \mathrm{~min}$. Each recording was analyzed twice. Primary analysis included a comparison of the assisted examination evaluated on-site vs the self-examination evaluated remotely in pairs. Secondary analysis was conducted by an independent expert who evaluated the unpaired recordings. Baseline fetal heart rate (BFHR) values were compared independently.

Results. We found that patients were more likely to perform inconclusive recordings than experienced midwives; however, the self-examination feasibility was satisfactory. The primary analysis showed $88.4 \%$ agreement of the recorded pairs; $11.6 \%$ of inconsistent pairs were due to inter-observer variability or medical reasons. The independent expert's analysis showed $97.1 \%$ agreement between the assisted and unassisted examinations. Paired t-test for BFHR values showed a statistically significant but clinically negligible mean difference between the 2 devices at $1.75 \mathrm{bpm}$.

Conclusions. The CTG examinations performed using mobile devices present satisfactory feasibility and equivalent diagnostic value compared to conventional devices, while the remote evaluation of recordings is as reliable as on-site analysis. Remote pregnancy surveillance is safe, effective and may be implemented into everyday obstetric care.

Key words: teleCTG, mobile CTG, telemedicine, eHealth, remote pregnancy monitoring 


\section{Background}

Healthcare is facing new challenges with regard to the growing number of chronic diseases, resulting in increasing direct and indirect costs, an insufficient number of medical professionals in relation to patient needs, and the growing expectations to provide quality care. One of the single most effective approaches to dealing with such challenges is to improve patient engagement by enabling individuals to manage their own health. Concomitantly, we are witnessing the emergence of new systems and services using electronic communication, referred to as eHealth or telemedicine, including web-based or mobile informative and decision-making applications, teleconsultations and remote monitoring. ${ }^{1}$ These technologies enable a shift from hospital-centered to patient-centered care. Telemedicine can also be used to improve access to medical services, which makes it applicable for rural areas and underdeveloped countries, ${ }^{2,3}$ where the concentration of health centers is low.

Telemedicine is increasingly used in obstetrics, as young women in their reproductive years are frequent users of the Internet, social media and smartphone applications. ${ }^{4}$ At the same time, the demand for fetal monitoring and constant reassurance is high amongst pregnant women. ${ }^{5}$ Telemedicine applications in obstetrics can be categorized depending on the form of service provided (educational, teleconsultations, remote monitoring) or depending on the problem addressed (lifestyle issues, gestational diabetes, mental health, etc.). Many of the applications have been tested in the past few years and positive effects have been shown (reviewed by van den Heuvel et al. $^{6}$ ); however, most of the studies lack an endpoint related to its clinical impact, which still remains to be determined.

Remote pregnancy monitoring is perceived to be one of the most promising telemedical applications. Antepartum fetal assessment is used in pregnancies with a high risk of perinatal morbidity and mortality owing to pre-existing maternal conditions, pregnancy-related conditions, ${ }^{7}$ intrauterine fetal death in the past, or in the case of overdue pregnancy. Testing options include the nonstress test (NST) based on a fetal heart rate (FHR) recording, which has been in clinical use for over 4 decades. The NST is based on the premise that the FHR, which is not acidotic or neurologically depressed, will temporarily accelerate with fetal movement. Heart rate reactivity is thought to be a good indicator of normal fetal autonomic function ${ }^{8}$ and a normal NST result is, in most cases, highly reassuring, as indicated by the high negative predictive value. ${ }^{9,10}$ Loss of reactivity is most commonly associated with fetal sleep cycles but may result from any cause of central nervous system depression, including fetal hypoxia and academia. ${ }^{8}$ The primary objective of perinatal patient management is to discover signs and symptoms of early stage hypoxia. This has implications not only in acute care, but may also affect the quality of an entire future life burdened with the consequences of hypoxia. ${ }^{11}$

The method routinely used for antenatal monitoring is cardiotocography (CTG), which allows for simultaneous detection of FHR (C - cardio) with an ultrasound transducer, and uterine contractions with a tocodynamometer ( $\mathrm{T}$ - toco), and a graphic $(\mathrm{G})$ presentation of their values as a function of time. ${ }^{12}$ Contemporary CTG devices are also able to detect maternal heart rate (MHR) and fetal movements, or allow the mother to manually mark fetal movements. The CTG examination is easy to perform, safe and completely non-invasive, which makes it a viable tool for patient self-monitoring. Even more importantly, CTGbased NST are considered safe for remote monitoring due to its low false-negative rate. ${ }^{7}$

Hod and Kerner ${ }^{7}$ identified the usefulness criteria for remote monitoring: 1) feasibility in patient's self-use and diagnostic similarity to traditional methods; 2) improvement of access to healthcare; 3 ) similarity in maternal and neonatal outcomes, compared to traditional methods; 4) patient and clinician satisfaction; and 5) cost-effectiveness. Even though it has been 16 years since the publication, none of these areas have been sufficiently examined and all still need more research, especially clinical outcomes, feasibility and diagnostic equivalence, as technology is constantly changing.

\section{Maternal and neonatal outcomes}

Kitagawa et al. ${ }^{13}$ found that home monitoring was equally as effective as ambulatory hospital management in preventing adverse events in high-risk women. Another study compared modes of delivery and complications postpartum between home-monitored high-risk patients and patients admitted to the hospital. ${ }^{14}$ There were no statistically significant differences between the 2 groups. Moore and Sill ${ }^{15}$ showed that the number and duration of hospital admissions for fetal surveillance were reduced in a homemonitored, high-risk patient group, without an increase in C-section and forceps delivery rates. Di Lieto et al. ${ }^{16,17}$ described the clinical results of the first 5 working years of a telemedicine project based on computerized telecardiotocography. The project embraced 1,873 low- and highrisk patients who delivered 5,830 CTG tracings. The authors found good neonatal outcomes, no false-negative results and no increase in $\mathrm{C}$-section rate.

Due to the function of uterine contraction activity monitoring, CTG is also suitable for early detection of threatened premature delivery symptoms in order to initiate treatment earlier. ${ }^{13}$ Studies have demonstrated that transmitting uterine activity by telecommunication resulted in significantly prolonged pregnancy survivals, ${ }^{18,19}$ while newborns were less likely to be of low birth weight or to be admitted to the neonatal intensive care unit, when a telemonitoring group was compared with a standard care group. ${ }^{19,20}$ 


\section{Feasibility and diagnostic equivalence}

A prerequisite for positive clinical outcomes from remote monitoring is the ability for a pregnant patient to properly perform an examination herself. It was shown that patients were equally as able as midwives to perform accurate CTG fetal monitoring ${ }^{15,21}$; however, the quality of the recorded data can be correlated with maternal body mass index (BMI). ${ }^{21}$ Reece et al. ${ }^{22}$ performed a controlled clinical trial on 60 patients who performed home based non-stress tests, followed by NCT performed by a midwife at the hospital within $60 \mathrm{~min}$. The pairs of tests were independently reviewed by 2 investigators and all were judged satisfactory for interpretation. Remote maternal-fetal monitoring is also feasible in resource-constrained environments, as was shown on a group of 153 high-risk pregnant indigenous Mayan women receiving either remote monitoring ( $\mathrm{n}=74$ ) or standard of care $(\mathrm{n}=79)$. Health outcomes were not statistically different between the 2 groups, while remote monitoring resulted in a markedly increased adherence (94.3\% vs $45.1 \%) .{ }^{23}$

Altogether, the data so far shows that home FHR monitoring is safe and feasible even in high-risk patients, as it can be easily and reliably performed without worsening medical outcomes, while patient satisfaction and overall acceptance remains promising. ${ }^{21}$

As more than 10 years have passed since the publication of most of the cited papers, during which the technology has evolved, and since diagnostic equivalence of remote versus conventional CTG monitoring was never properly studied, we aimed 1) to compare the diagnostic usefulness between an examination performed by a patient with a mobile CTG device and an examination performed by a medical professional with a stationary CTG device; and 2) to evaluate the quality of CTG analysis performed remotely.

\section{Material and methods}

The study was conducted at the $1^{\text {st }}$ Department and Clinic of Gynecology and Obstetrics at Wroclaw Medical University, Poland. The protocol was approved by the Bioethics Committee at the university (approval No. KB-370/2018). Participants were recruited from patients admitted to the Gynecology and Obstetrics unit based on the following inclusion criteria: gestational age between 27 and 42 weeks, singleton pregnancy, and BMI before pregnancy $18.50-29.99 \mathrm{~kg} / \mathrm{m}^{2}$. Patients were excluded from the study in the case of: multiple pregnancy, active medical implants, lethal fetal defects, chronic or acute skin lesions, or allergy to any of the substances found in the device probes, belts or ultrasound gel. Twenty-seven patients were enrolled after providing informed consent, of which 18 provided CTG recordings for analysis. The remaining 9 patients were excluded from the study as they were unable to deliver results that met the protocol criteria (i.e., the interval between examinations was exceeded or no recording from the mobile device was delivered). A total of 164 recordings were collected, including 82 from a stationary device (Corometrics model 172; GE Healthcare, Chicago, USA) and 82 from a mobile device (Pregnabit; Nestmedic, Wrocław, Poland).

\section{Study group}

The CTG examinations included in the analysis were performed on 18 women, 27-37 years old (mean age: 32.2 years). Body mass index before pregnancy ranged from $17.8 \mathrm{~kg} / \mathrm{m}^{2}$ to $29.0 \mathrm{~kg} / \mathrm{m}^{2}$ (mean: $21.5 \mathrm{~kg} / \mathrm{m}^{2}$ ), while gestational age at the moment of inclusion was between 32 weeks and 40 weeks (mean: 35.4 weeks). All participants had an indication for increased CTG supervision, with 8 patients having a history of miscarriage or fetal death.

\section{Study design}

The patients included in the study were trained in operating the mobile device. The CTG examinations with a stationary device were carried out by midwives in accordance with standard of care, twice daily for at least $30 \mathrm{~min}$ per examination. Within 30 min of completing the conventional recording, the patient carried out the examination using the mobile device on her own, without any assistance from a medical professional. The $2^{\text {nd }}$ examination took another $30 \mathrm{~min}$. Afterwards, the patients were asked to complete the questionnaire.

A single result meant a pair of CTG recordings, one using the stationary device and the second recorded from the mobile device, obtained from the same patient, at an interval of no more than $30 \mathrm{~min}$. The recording was considered technically incorrect when there was less than 20 min of FHR signal recorded or if there was no TOCO signal. Results where one of the recordings was technically incorrect were excluded from further analysis.

\section{Primary analysis (on-site vs remote)}

Tracings from the stationary device were analyzed visually on-site by the investigators (physicians); reactivity, presence of accelerations and decelerations, variability, number of fetal movements, and uterine contraction activity were assessed. Baseline fetal heart rate (BFHR) was calculated using Monako software (Institute of Medical Technology and Equipment, Zabrze, Poland). Based on the above factors, the following status' were assigned to the recordings: normal, suspicious, pathological, or technically incorrect.

The tracings obtained from the mobile device were sent directly from the device to the telemedical center (Medical Telemonitoring Center (MTC), Wrocław, Poland) via GSM communication and were assessed remotely 


\section{A. primaryanalysis}

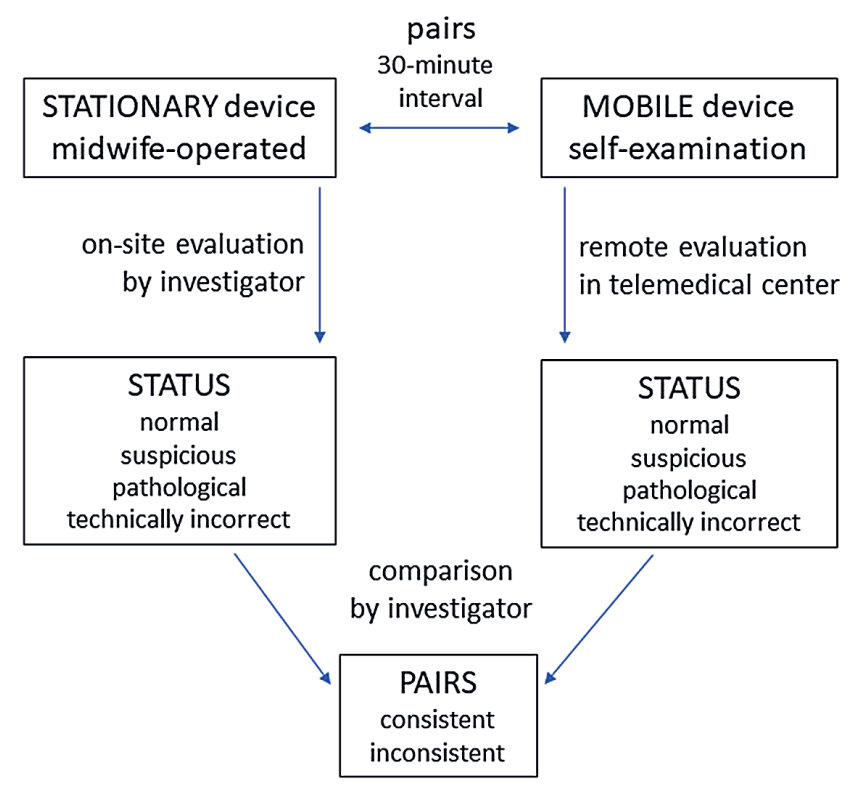

Fig. 1. Primary (A) and secondary (B) analysis schemes

by the MTC staff according to UK National Institute for Health and Care Excellence (NICE) 2001 guidelines. Reactivity, the presence of accelerations and decelerations, variability, number of fetal movements, and uterine contraction activity were assessed. Baseline fetal heart rate was calculated using the Pregnabit telemedical platform. Based on the above factors, the recordings were assigned the status normal, suspicious, pathological, or technically incorrect. Descriptions were available via the Pregnabit platform to the investigators, who further compared the recording statuses and marked the results as consistent or inconsistent. The primary analysis scheme is presented in Fig. 1A.

\section{Secondary analysis (independent expert)}

After all 82 results (pairs of tracings) were collected, and the results were coded, unpaired and delivered to an independent expert (obstetrician) who assessed them individually. All recordings were assigned a status as above (normal, suspicious, pathological, or technically incorrect) and then were paired again. The degree of agreement between the recordings in a pair was measured as consistent or inconsistent. The secondary analysis scheme is presented in Fig. 1B.

\section{Statistical analysis}

The frequency of a particular status in groups was assessed using the McNemar's $X^{2}$ test with continuity correction. The inter-rater agreement was tested using the prevalence-adjusted bias-adjusted kappa (PABAK) coefficient for qualitative variables. Normality of BFHR

\section{B. secondary analysis}

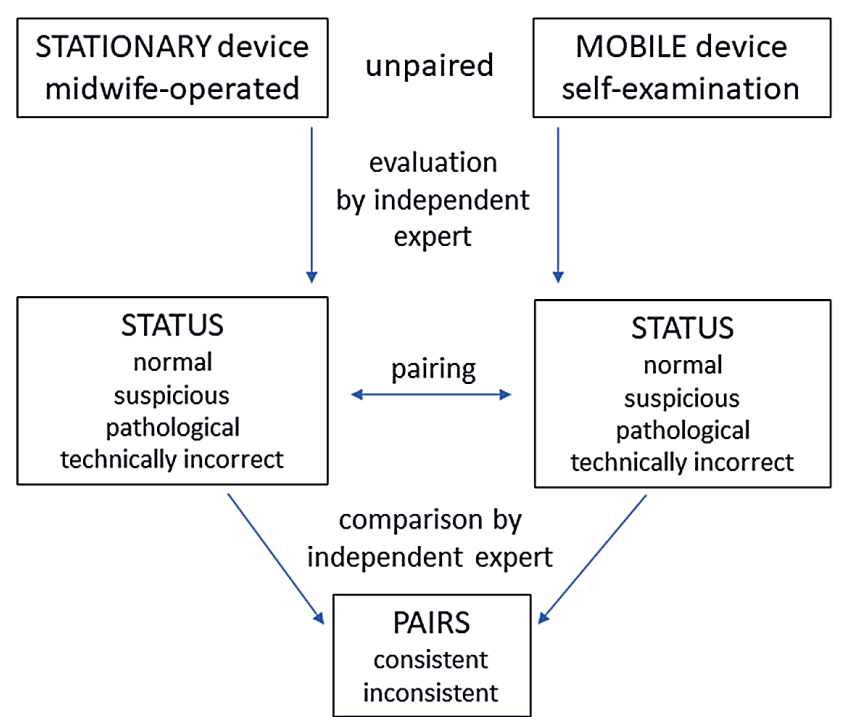

measurements was assessed using the Shapiro-Wilk test. The BFHR measurements were compared with a paired t-test and Cohen's d coefficient. The agreement between BFHR measurements was analyzed using Bland-Altman methodology. The relationship between the patient's status and BMI or gestational age was examined using analysis of variance (ANOVA). Analyses were performed in $\mathrm{R}$ for Windows statistical software v. 3.5.2 (Microsoft Corp., Redmond, USA). ${ }^{24}$

\section{Results}

\section{Feasibility}

Eighty-two pairs of CTG tracings were collected (164 in total). Each pair consisted of a single tracing from the stationary device registered by a midwife and a single tracing from the mobile device registered by the patient herself, taken with an interval time no longer than $30 \mathrm{~min}$.

Among the 82 recordings from the stationary device, we found 2 results (2.4\%) that were inappropriate for analysis (technically incorrect) because of a recording time that was too short (less than $20 \mathrm{~min}$ ). Among the recordings from the mobile device, 13 recordings (15.9\%) were technically incorrect, 8 due to interruptions in the FHR signal longer than 10 min and 5 due to a lack of TOCO signal. Two of the recordings with no TOCO signal were marked by the telemedical center as normal due to the correct recording of FHR; however, there were annotations in the descriptions with recommendations for the following examination, to correct the positioning of the TOCO probe and to restart it after positioning. 


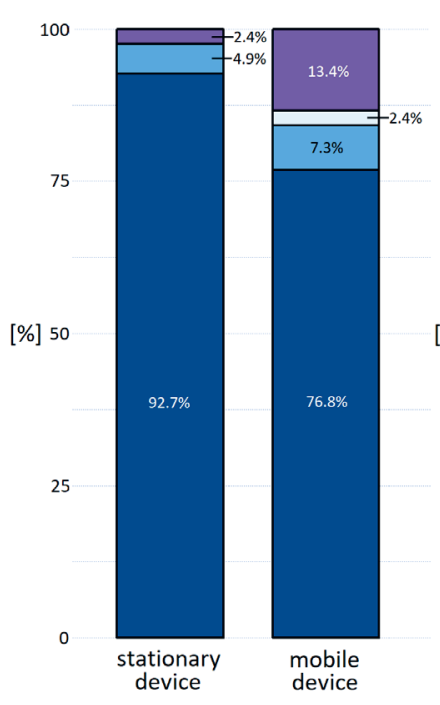

A. primary analysis

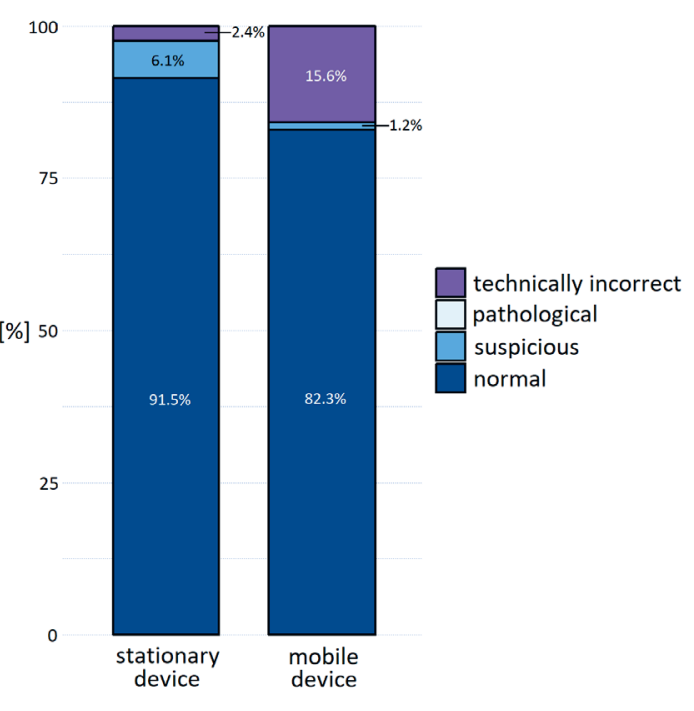

B. secondary analysis

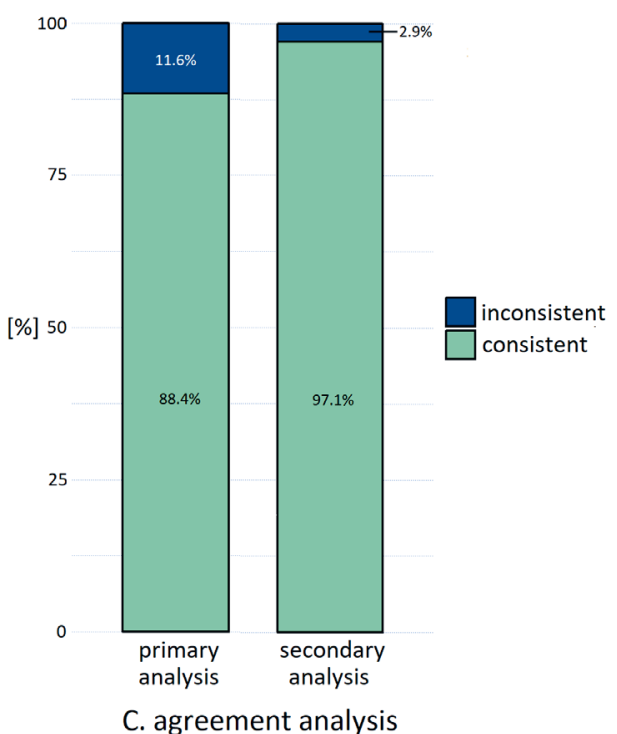

Fig. 2. A. Results of primary analysis (on-site vs remote). B. Results of secondary analysis (independent expert); C. Agreement analysis

McNemar's $\chi^{2}$ test showed that the difference in frequency of the technically incorrect recordings was statistically significant $(\mathrm{p}=0.027)$. Six out of 13 technically incorrect recordings using the mobile device came from only 2 patients, who we consider uncooperative (case 1: $3 / 6$ technically incorrect recordings; case 2: $3 / 4$ technically incorrect recordings). The poor cooperation was likely due to the fact that the patients were monitored either way and felt safe, so they did not feel the need to control the placement of the probes. Differences between the frequency of the other statuses were not statistically significant. We were unable to show that technically incorrect results occur significantly more often among patients with a higher BMI or lower gestational age.

In summary, patients were more likely to perform inconclusive recordings than experienced midwives; however, the feasibility of self-examination was satisfactory (84.1\% of conclusive recordings). After removal of the 2 uncooperative patients, the percentage of conclusive examinations rose to $90.1 \%$. Each time, in the case of a technically incorrect recording, the telemedical center gave the recommendation to 'repeat the examination' along with directions on how to place the probes correctly over the abdomen.

\section{Diagnostic comparability}

Pairs in which one of the recordings was technically incorrect were removed from further analysis; in pairs categorized as technically incorrect only due to a lack of TOCO signal, BFHR value was included into BFHR agreement analysis.

The primary analysis was performed by comparing the recording status in pairs - the status for the stationary recording was given by the investigator on-site, while the status for the mobile recording was provided remotely by the telemedical center. Both statuses were compared by the investigator. Sixty-nine pairs were included; agreement was found in 61 pairs $(88.4 \%)$, while inconsistency was in 8 pairs (11.6\%). The PABAK coefficient for the conformity of the quality variables was 0.77 (95\% CI $=0.57-0.90)$ and indicated substantial agreement in the primary analysis. The results of the primary analysis are summarized in Fig. 2A. Inconsistent pairs were analyzed once again by direct comparison of the recordings to identify the causes of the inconsistency; the findings are listed in Table $1 \mathrm{~A}$.

There was no disagreement identified that could be attributed to the differences between the 2 devices. Two cases of disagreement occurred because of physiological or medical reasons due to the time shift between the 2 consecutive recordings. This is a consequence of the study design, as it is practically impossible to place 4 probes on the patient's abdomen simultaneously. Additionally, there is only 1 optimal location for FHR detection, thus, in the case of simultaneous recordings, one of the devices would necessarily be condemned to a worse position, which could lead to even more technically incorrect results. Five cases of disagreement resulted from interobserver variability; this was an effect of the cautious approach of specialists in the telemonitoring center, who assessed the recordings remotely with no contact with the patients and no prior knowledge about their gestational age, which normally affects the diagnosis. One mistake was identified in the status given by the telemedical center; however, it did not change the final recommendation, which would be to 'repeat the examination' either way, for both 'suspicious' or 'technically incorrect' results.

Secondary analysis was carried out by an independent expert in order to eliminate inter-observer variability. The analysis was partially blinded as the expert was provided unpaired recordings and assessed them independently. 
Table 1. Results of direct comparison of tracings from pairs assigned as inconsistent during primary (A) and secondary (B) analysis

\begin{tabular}{|c|c|c|c|c|c|}
\hline \multirow{2}{*}{ No. } & \multicolumn{2}{|r|}{ Stationary device } & \multicolumn{2}{|r|}{ Mobile device } & \multirow{2}{*}{ Cause of inconsistency } \\
\hline & status & justification of the status & status & justification of the status & \\
\hline \multicolumn{6}{|c|}{ A. Primary analysis } \\
\hline 1 & normal & $\begin{array}{l}\text { normal FHR tracing despite } \\
\text { uterine contraction activity }\end{array}$ & pathological & $\begin{array}{l}\text { regular uterine } \\
\text { contractions, } \\
\text { normal FHR tracing }\end{array}$ & $\begin{array}{l}\text { inter-observer variability - pathological } \\
\text { status in the remote evaluation is equivalent } \\
\text { to recommendation 'contact the doctor' according } \\
\text { to the telemedical center standards, which is justified } \\
\text { in case of regular uterine contractions, without } \\
\text { the possibility of contacting the patient by phone; } \\
\text { the specialist in the telemedical center had no prior } \\
\text { knowledge regarding gestational age of the study } \\
\text { participants which affected the interpretation; } \\
\text { the signal of uterine contraction activity was } \\
\text { identical in both recordings }\end{array}$ \\
\hline 2 & suspicious & $\begin{array}{c}\text { short-term FHR } \\
\text { decreases }<100 \text { bpm }\end{array}$ & normal & $\begin{array}{l}\text { normal FHR tracing, } \\
\text { no uterine activity }\end{array}$ & $\begin{array}{c}\text { medical cause - FHR decreased below } 100 \text { bpm, } \\
\text { which requires further observation; however, } \\
\text { the most probable cause in this case was accidental } \\
\text { detection of MHR by the FHR probe (recordings } \\
\text { shown in the Fig. 3B) }\end{array}$ \\
\hline 3 & normal & normal FHR tracing & suspicious & $\begin{array}{l}\text { no fetal movements } \\
\text { marked by the patient }\end{array}$ & $\begin{array}{l}\text { inter-observer variability - while there was no } \\
\text { possibility to contact the patient, telemedical center } \\
\text { indicated the need for further observation by giving } \\
\text { the status 'suspicious' }\end{array}$ \\
\hline 4 & normal & normal FHR tracing & suspicious & transient tachycardia & $\begin{array}{l}\text { physiological cause - during the recording with } \\
\text { mobile device, twice as many fetal movements were } \\
\text { marked by the patient compared to the recording } \\
\text { using the stationary device; this was probably } \\
\text { reflected by acceleration of the heart rate (BFHR } \\
\text { value from mobile device was } 156 \text { bpm vs } 140 \text { bpm } \\
\text { from stationary device) }\end{array}$ \\
\hline 5 & normal & normal FHR tracing & suspicious & $\begin{array}{l}\text { FHR variability temporarily } \\
\text { reduced; only } 1 \text { fetal } \\
\text { movement }\end{array}$ & $\begin{array}{l}\text { inter-observer variability - assessment } \\
\text { of the telemedical center was conservative due } \\
\text { to the lack of telephone contact with the patient }\end{array}$ \\
\hline 6 & normal & normal FHR tracing & suspicious & $\begin{array}{c}\text { lack of uterine activity } \\
\text { tracing }\end{array}$ & $\begin{array}{l}\text { wrong status given by the telemedical center } \\
\text { - the right status was 'technically incorrect'; it was } \\
\text { advised to repeat the examination }\end{array}$ \\
\hline 7 & normal & normal FHR tracing & pathological & $\begin{array}{l}\text { regular uterine } \\
\text { contractions, } \\
\text { normal FHR tracing }\end{array}$ & as in No. 1 \\
\hline 8 & normal & normal FHR tracing & suspicious & $\begin{array}{l}\text { regular uterine } \\
\text { contractions, } \\
\text { normal FHR tracing }\end{array}$ & $\begin{array}{l}\text { inter-observer variability - pathological } \\
\text { status in the remote evaluation is equivalent } \\
\text { to recommendation 'contact the doctor' according } \\
\text { to the telemedical center standards, which is justified } \\
\text { in case of regular uterine contractions, without } \\
\text { the possibility of contacting the patient by phone; } \\
\text { the specialist in the telemedical center had no prior } \\
\text { knowledge regarding gestational age of the study } \\
\text { participants which affected the interpretation; } \\
\text { the signal of uterine contraction activity was } \\
\text { identical in both recordings }\end{array}$ \\
\hline \multicolumn{6}{|c|}{ B. Secondary analysis } \\
\hline 1 & suspicious & $\begin{array}{l}\text { FHR variability temporarily } \\
\text { reduced }\end{array}$ & normal & $\begin{array}{l}\text { normal FHR tracing, not } \\
\text { regular uterine contractions }\end{array}$ & $\begin{array}{l}\text { physiological cause - reduced variability } \\
\text { occurring during the last } 30 \text { min of recording with } \\
\text { the stationary device (total recording length }-1 \mathrm{~h} \text { ) } \\
\text { may be, but not necessarily, an indication for further } \\
\text { monitoring; result at the borderline of the standard }\end{array}$ \\
\hline 2 & suspicious & $\begin{array}{l}\text { FHR variability temporarily } \\
\text { reduced }\end{array}$ & normal & $\begin{array}{l}\text { normal FHR tracing, not } \\
\text { regular uterine contractions }\end{array}$ & $\begin{array}{l}\text { physiological cause - reduced variability } \\
\text { in the recording with the stationary device may } \\
\text { be, but not necessarily, an indication for further } \\
\text { monitoring; result at the borderline of the standard }\end{array}$ \\
\hline
\end{tabular}

FHR - fetal heart rate; MHR - maternal heart rate; BFHR - baseline fetal heart rate. 
Fifteen recordings were assigned as 'technically incorrect' - 13 from the mobile device and 2 from the stationary device. After assessment, the recordings were paired again; pairs with technically incorrect recordings $(14 ; 17.1 \%)$ were excluded from further analysis. The remaining 68 pairs were analyzed for agreement based on the status given. Sixty-six pairs (97.1\%) were found consistent, while 2 pairs (2.9\%) were found to be inconsistent. The PABAK coefficient for the secondary analysis was $0.94(95 \% \mathrm{CI}=0.80-0.99)$, indicating an excellent agreement. The results from the secondary analysis are summarized in Fig. 2B and 2C. Inconsistent pairs were analyzed as previously by direct comparison of the tracings to identify the causes of inconsistency; the findings are listed in Table 1B. An example of consistent tracings is shown in Fig. 3A, while an example of inconsistent recordings is shown in Fig. 3B (case 2 from Table 1A - inconsistency due to medical reason).

As before, there was no inconsistency that resulted from the differences between devices. Both pairs assigned as 'inconsistent' were due to physiological variability of FHR and referred to results at the borderline of the standard. It must be noted that neither of the 2 inconsistent pairs from the secondary analysis overlaps with any inconsistent pair from the primary analysis. This confirms that CTG is largely affected by inter-observer variability on one hand, and on the other, that the pairs identified as inconsistent were in fact technically consistent.

In order to assess the quality of remote analysis, we compared statuses given to the same recordings from the mobile device by the telemedical center and the independent expert. We found 8 disagreements amongst the assessed recordings, of which 7 coincided with inconsistencies from the primary analysis. Identified differences were attributed to the excessively conservative assessment by the telemedical center (6 cases) and to erroneous evaluation of the recordings that should not be analyzed (technically incorrect -2 cases).

Next, the calculated BFHR values were compared. Paired t-test showed that the mean difference between 2 devices was $1.75 \mathrm{bpm}(\mathrm{p}=0.017$; 95\% CI $=0.33-3.17$ ), which we consider very low and clinically irrelevant. Cohen's d coefficient, which evaluates the strength of the relationship between the device used and the BFHR measurement, was $0.29(95 \% \mathrm{CI}=0.04-0.62)$ and showed little effect of the device type on the BFHR value. The BlandAltman plot suggests an acceptable range of difference between BFHR measurements of -10.1-13.6. According to the Gaussian distribution in the population, approx. 95\% of observations should be contained in less than 2 standard deviations (SD). In our study, 3 observations $(4.2 \%)$ go beyond the range, which is less than $5 \%$ of the permissible error. The results of the BFHR analysis are shown in Fig. 4.

Altogether, the data presented indicates that there is an excellent technical diagnostic comparability between conventional and mobile CTG devices. Remote evaluation by the telemedical center is reliable - however, sometimes too conservative and cautious, but in a way that does not adversely affect the final recommendations.

\section{Adverse events}

During the course of the study, 1 adverse event was noted. A single patient reported mild and transient skin irritation, with redness in the area where the ultrasound gel was applied while using the mobile device. The redness resolved itself within $1 / 2 \mathrm{~h}$.

\section{Patient survey}

Eighteen completed questionnaires were collected. Most patients reported that CTG self-examination using the mobile device was easy (28\%) or rather easy (61\%), even if localization of the FHR signal was sometimes difficult (difficult - 28\%; rather difficult - 50\%). Eightynine percent of the patients declared that the possibility to perform the examination at home would increase their sense of security. The most frequently listed situations in which patients would likely use remote fetal monitoring included: 1) days off when access to the physician is limited (72\%); 2) when there are identified factors that threaten the child or there is an increased risk of premature birth, but to an extent that does not require hospitalization (72\%); 3) overdue pregnancy (56\%).

\section{Discussion}

In a situation in which an indication for intensified CTG surveillance occurs, a physician faces the decision whether to admit the patient to the ward or recommend that she visit the clinic several times a week. Both options are inconvenient for the patient since, instead of being at home, she must stay at the hospital or in the best-case scenario travel there a few times a week. This situation also results in an overcapacity in hospital wards, extended queues at the clinic and medical personnel overwork, as well as an increase in the cost of prenatal care.

Another option that has emerged in recent years is remote fetal surveillance with the use of mobile CTG devices; however, this is still rarely used due to limited trust in telemedical solutions. The lack of trust results partly from poor experiences and lack of knowledge of these solutions, and partly from limited scientific data that confirms its clinical effectiveness and safety.

In this study, we aimed to compare the diagnostic usefulness of CTG self-examination using a mobile device to examination performed by a medical professional using a stationary device, and to evaluate the quality of CTG analysis performed remotely. We found that technically, the mobile and the stationary devices are indistinguishable, as shown by the mean difference in the BFHR 
sivis 12

stratc

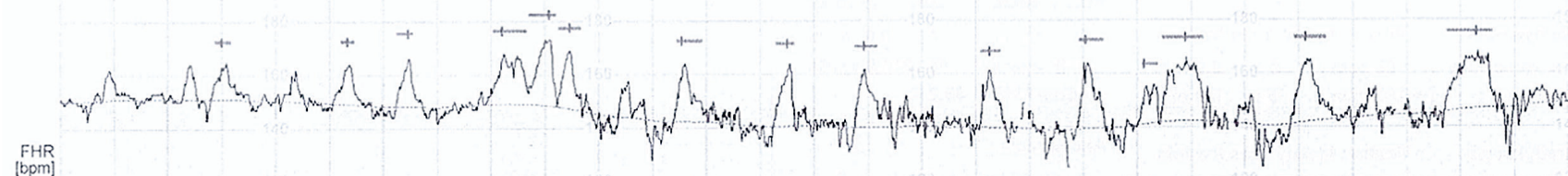
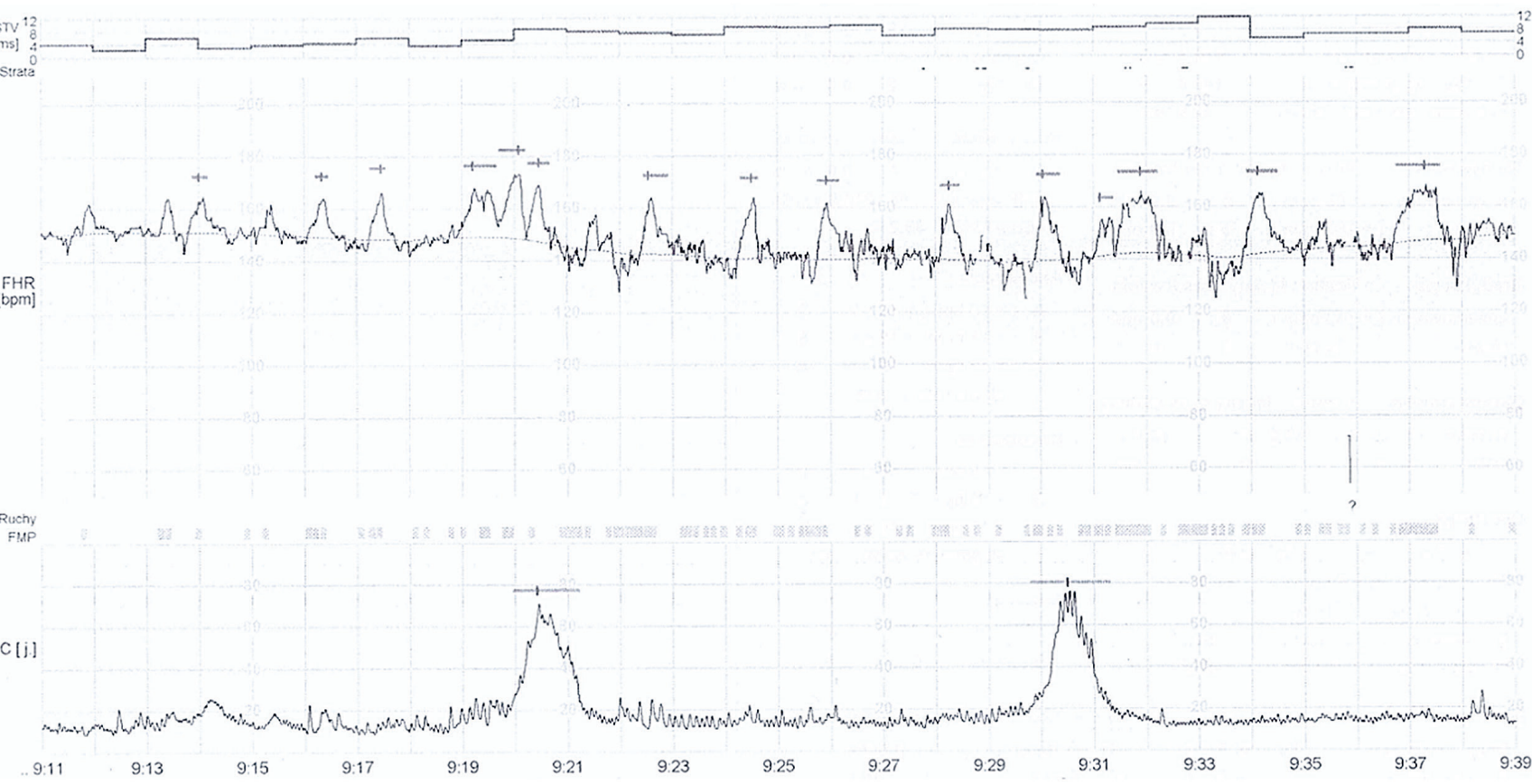

FHR/HR [bpm]

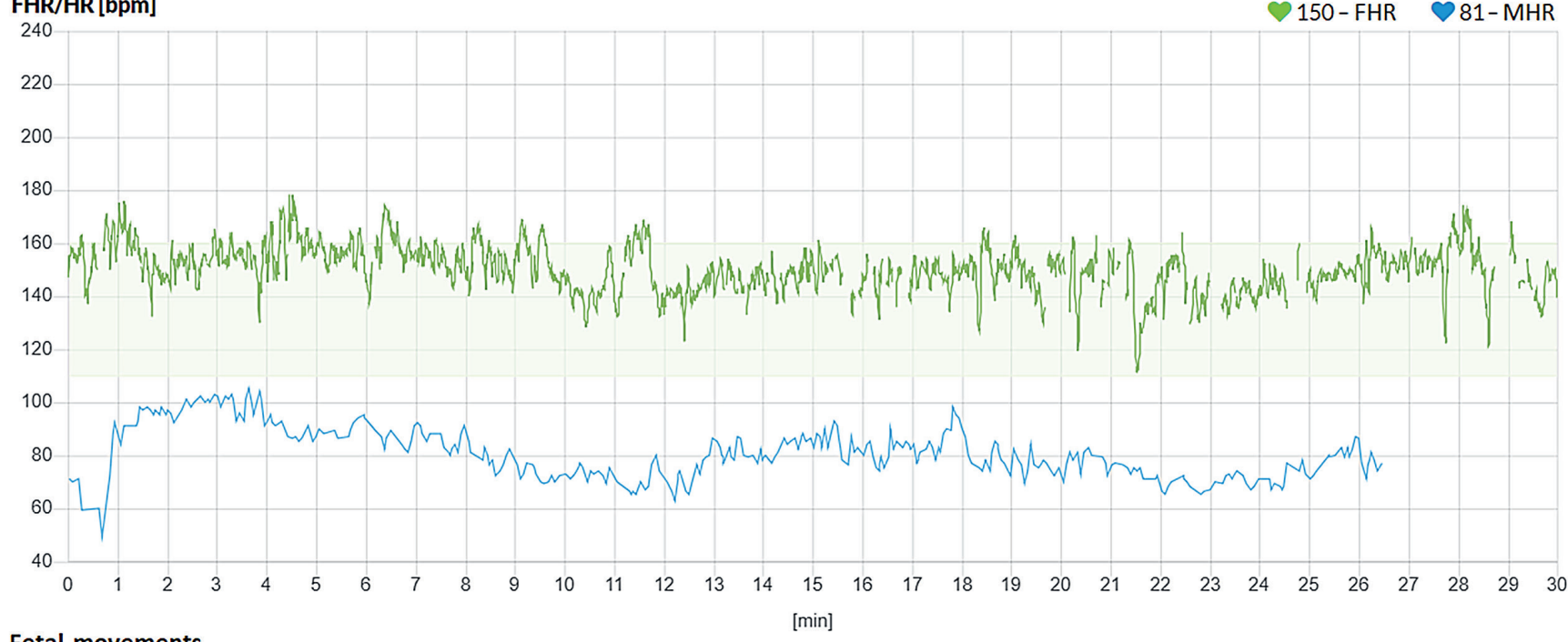

\section{Fetal movements}

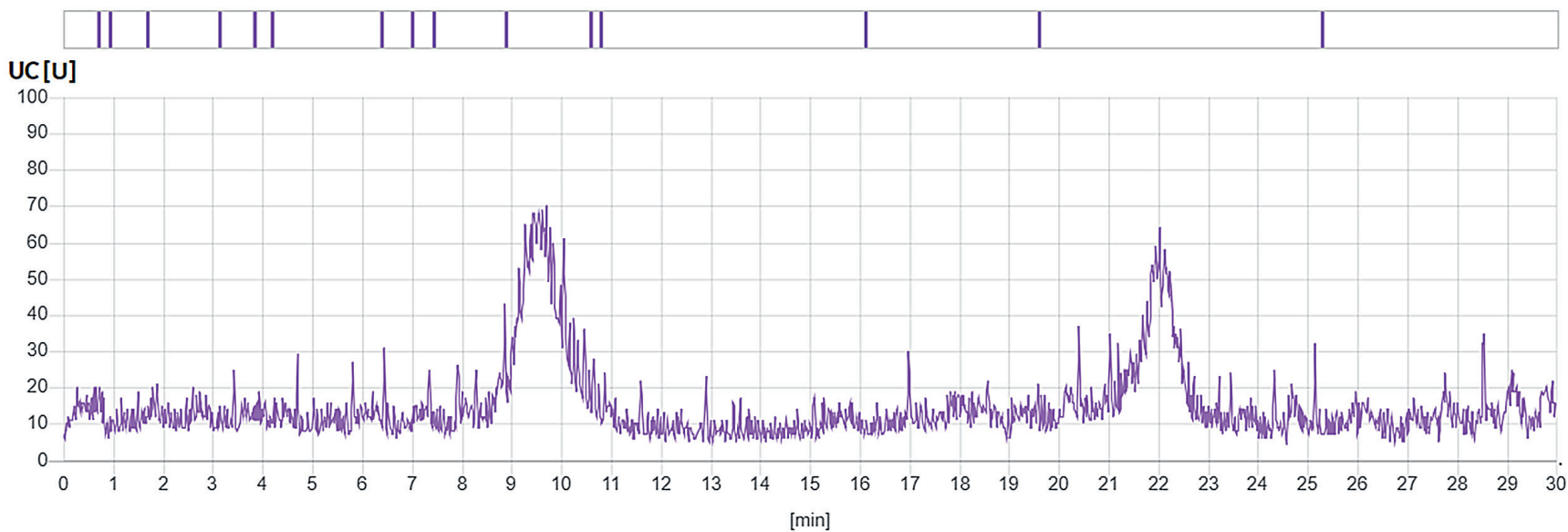

Fig. 3. A - pair of consistent recordings: upper - stationary device, lower - mobile device: upper - stationary device (suspicious), lower - mobile device (normal). Identified reasons of evaluation disagreement were FHR decreases $<100$ bpm during the $1^{\text {st }}$ recording, which most likely resulted from accidental detection of maternal heart rate by the FHR probe 


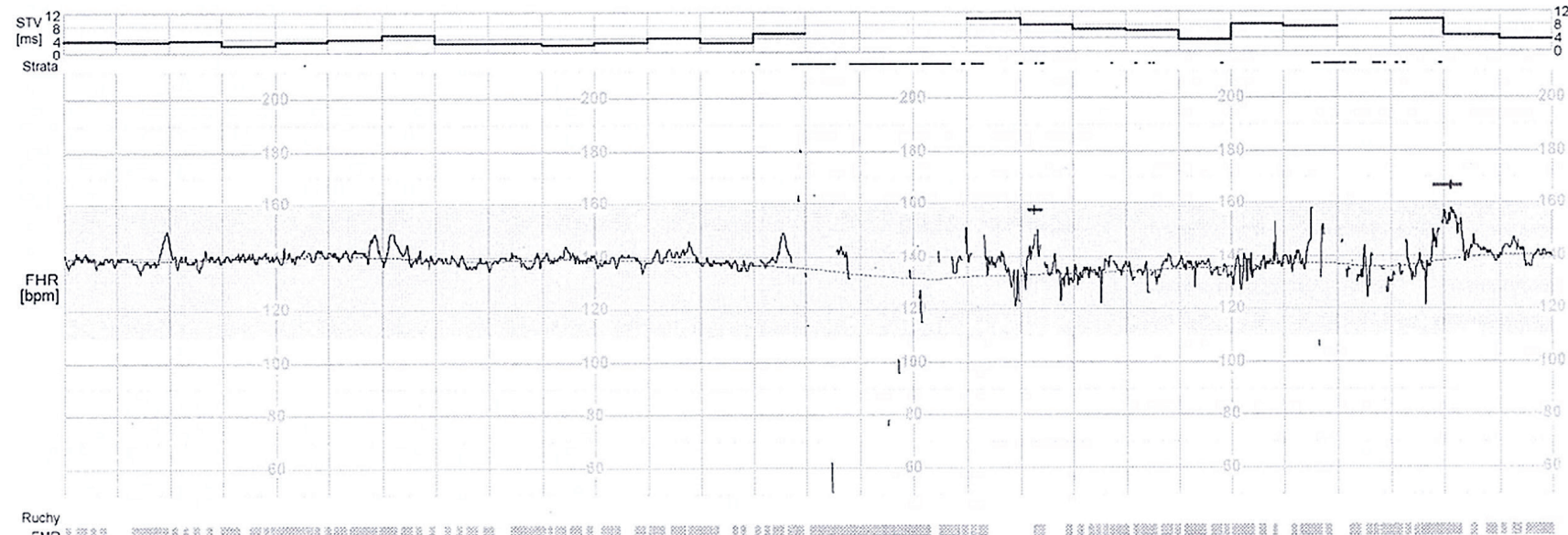

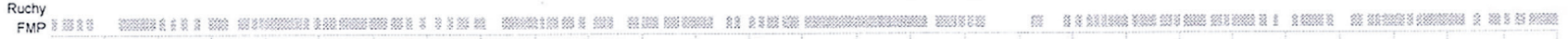

UC [j.]
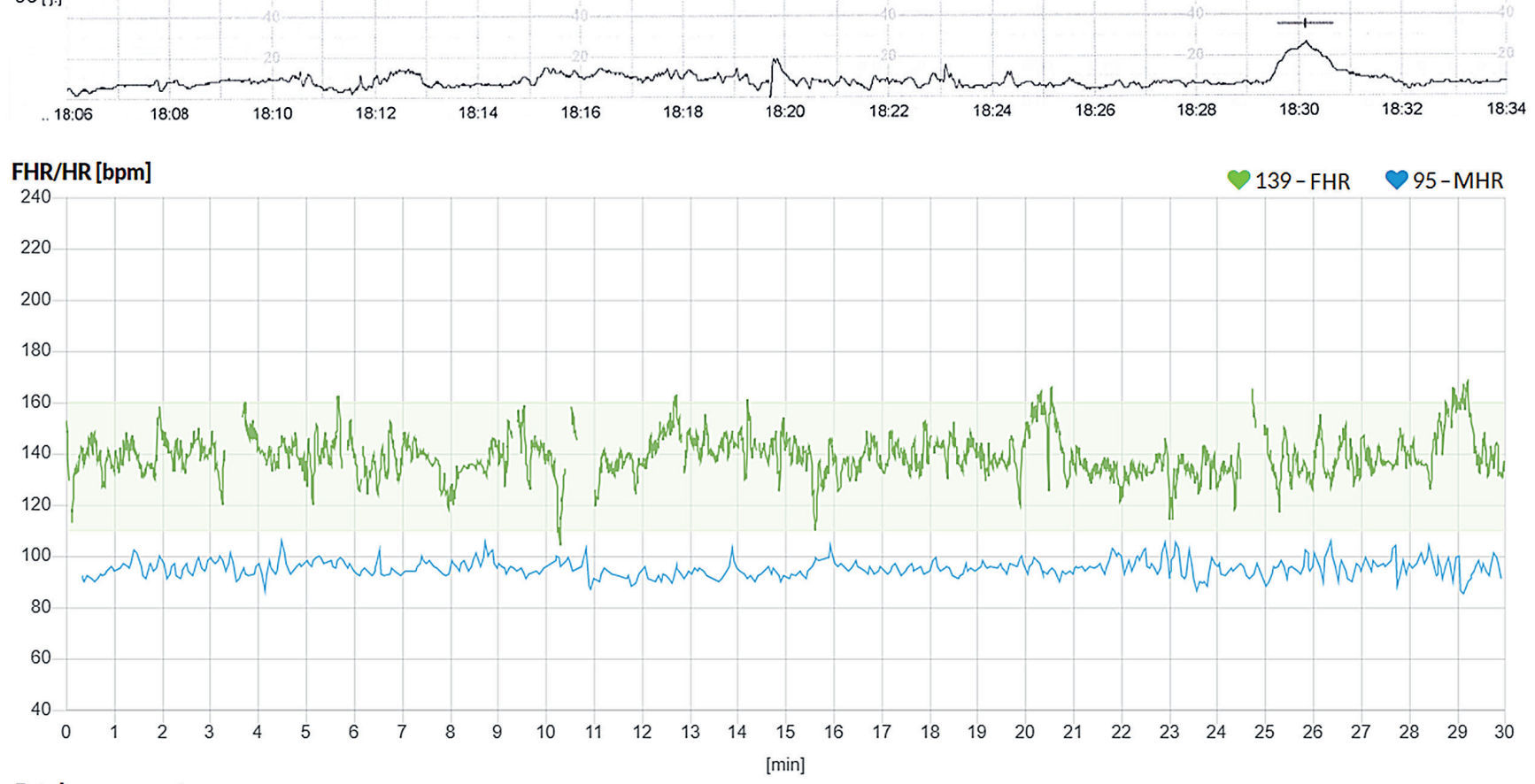

Fetal movements

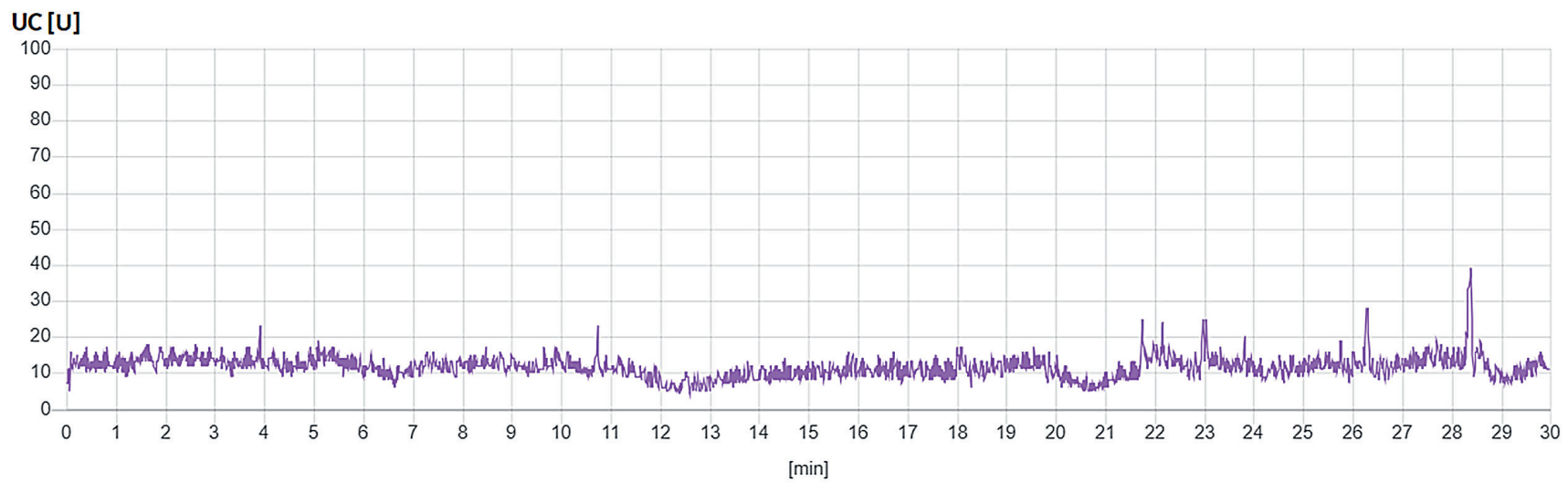

Fig. 3. B - pair of inconsistent recordings: upper - stationary device (suspicious), lower - mobile device (normal). Identified reasons of evaluation disagreement were FHR decreases $<100$ bpm during the $1^{\text {st }}$ recording, which most likely resulted from accidental detection of maternal heart rate by the FHR probe 
$\underset{160}{\mathrm{~A}}$

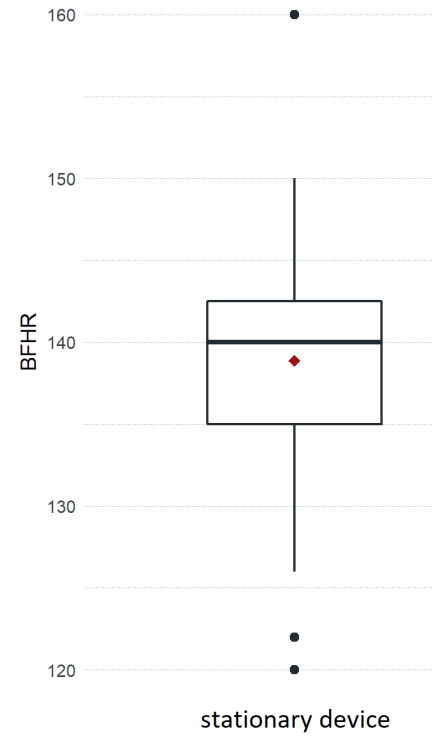

$\cdot$

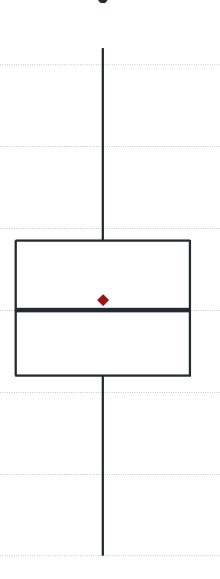

mobile device
B.

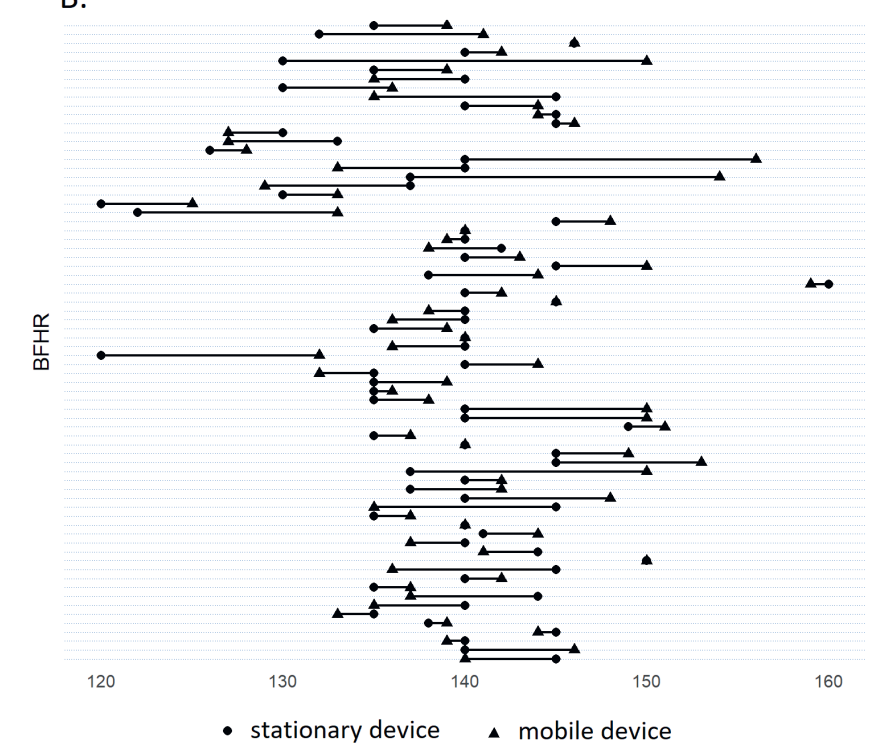

C.

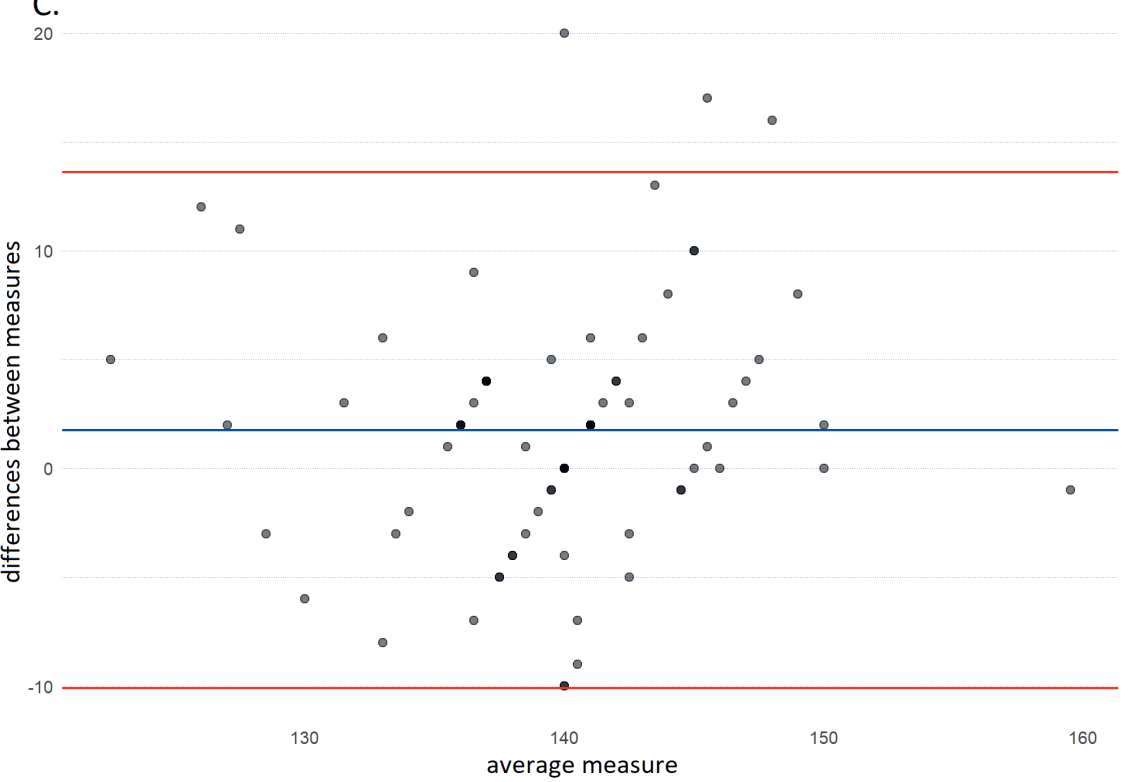

Fig. 4. Results of BFHR analysis: A. Box chart of BFHR measurements - the horizontal line represents the median, the dot represents the mean; B. Differences in BFHR values in pairs; C. Bland-Altman plot

measurement at $1.75 \mathrm{bpm}$ (less than the permitted measurement error of FHR probes, which is $2 \mathrm{bpm})$, comparison of CTG tracing assessments (97.1\% of consistent diagnoses in the independent expert analysis) and direct comparison of the recording graphs - even if the assessment of the recorded pairs was inconsistent, we were not able to identify any technical differences. Discrepancies resulted either from inter-observer variability or the study design, in which the time shift between the 2 examinations led to a physiological change of the fetus's state, which was reflected in the FHR recording.

Inter-observer variability is a known characteristic of CTG, ${ }^{25,26}$ as the diagnosis is mostly based on the subjective assessment of the graphical record and can be related to the professional experience of the interpreter.
Variability is the most prominent in borderline situations when the decision made can be either more or less cautious. A conservative approach was seen in telemedical center interpretations; however, under the study conditions, we found them justifiable. There were 2 main limitations for the center staff to make more accurate assessments: 1) no access to additional information about the patient and her condition, as it was impossible to contact the patient by phone (patients were hospitalized), which is standard in the center's normal operation; and 2) no information about the patient's gestational age (due to data anonymization), which strongly influences the diagnosis. In the situations described in Table 1 (No. 1, 7 and 8), the recordings were remotely described as pathological or suspicious only because of regular contraction activity of the uterus, while 
the FHR signal was physiological. It may seem exaggerated, however. If it concerned a patient under 36 weeks of pregnancy, regular contractions could be a sign of preterm delivery, which would definitely be a reason to contact the doctor ('pathological' status in the center's operation is equal to the recommendation to contact a doctor) or at least for further intensified surveillance. Such doubts do not apply to investigators on-site who had constant supervision over the patient.

One can conclude that excessively cautious assessments can lead to unnecessary visits to the clinic or unnecessary medical interventions; however, the literature does not confirm that remote fetal monitoring leads to either of them. On the contrary, the number of unnecessary visits decreases, while the number of $\mathrm{C}$-sections remains at a comparable level. The experience of an American obstetrics team running a remote prenatal care program, called ANGEL shows that based on a single telephone contact with the midwife, 676 emergency visits were avoided in 2016. ${ }^{27}$ This number could possibly be even greater with access to remote NST. This is why we consider direct contact with the patient crucial in remote monitoring. In a study where women undergoing labor induction with slow-releasing dinoprostone at home with constant remote monitoring of the fetus, it was shown on the basis of women's declarations, that contact with a medical professional is a prerequisite for feeling safe and secure. Women who had problems with reaching the hospital by phone experienced increased anxiety. ${ }^{28}$ The C-section rate for patients with diabetes managed by the ANGEL program was $26 \%$, compared to the $34 \%$ US national rate. ${ }^{27}$

Based on our study results, we assess the feasibility of CTG self-examination as satisfactory. After exclusion of the results of 2 poorly cooperating patients, the percentage of recordings appropriate for analysis was $90.1 \%$. Eighty-nine percent of patients who performed unassisted CTG examinations judged it as easy or rather easy to perform. Also $89 \%$ of the study participants declared that the possibility of performing NST at home would increase their sense of security. This often-neglected aspect is, however, worth considering in obstetric practice, especially when taking care of high-risk patients or patients with a history of intrauterine fetal death. Pregnancy with such a history is an emotionally challenging life event for women and adequate support during pregnancy should be considered as an essential component of quality maternal care. ${ }^{29}$

The academic community needs to develop evidence that will constitute the basis for the development of new care delivery models, including remote monitoring, as well as methods for providing the best patient-centered care. It is important that the future of medicine be determined by solid research and education. ${ }^{30}$ Our study provided the evidence that mobile CTG devices present an equivalent diagnostic value to conventional devices, and that remote recording evaluation is as reliable as on-site analysis and thus can be implemented in perinatal care.

\section{ORCID iDs}

Renata Pilarczyk (D) https://orcid.org/0000-0002-2818-6789 Mateusz Strózik (D) https://orcid.org/0000-0002-5533-3086 Lidia Hirnle (D) https://orcid.org/0000-0001-9789-5370

\section{References}

1. WHO Global Observatory for eHealth. mHealth: New horizons for health through mobile technologies: Second global survey on eHealth. Geneva, Switzerland: World Health Organization; 2011. https://www.who.int/goe/publications/goe_mhealth_web.pdf. Accessed February 19, 2019.

2. Lee SH, Nurmatov UB, Nwaru BI, Mukherjee M, Grant L, Pagliari C. Effectiveness of mHealth interventions for maternal, newborn and child health in low- and middle-income countries: Systematic review and meta-analysis. J Glob Health. 2016;6(1):010401. doi:10.7189/jogh. 06.010401

3. Sondaal SF, Browne JL, Amoakoh-Coleman M, et al. Assessing the effect of mhealth interventions in improving maternal and neonatal care in low- and middle-income countries: A systematic review. PLoS One. 2016;11(5):e0154664. doi:10.1371/journal.pone.0154664

4. Wallwiener S, Müller M, Doster A, et al. Pregnancy eHealth and mHealth: User proportions and characteristics of pregnant women using web-based information sources: A cross-sectional study. Arch Gynecol Obstet. 2016;294(5):937-944.

5. Grassl N, Nees J, Schramm K, et al. A Web-based survey assessing the attitudes of health care professionals in Germany toward the use of telemedicine in pregnancy monitoring: Cross-sectional study. JMIR Mhealth Uhealth. 2018;6(8):e10063. doi:10.2196/10063

6. van den Heuvel JF, Groenhof TK, Veerbeek JH, et al. eHealth as the next-generation perinatal care: An overview of the literature. J Med Internet Res. 2018;20(6):e202. doi:10.2196/jmir.9262

7. Hod M, Kerner R. Telemedicine for antenatal surveillance of highrisk pregnancies with ambulatory and home fetal heart rate monitoring: An update. J Perinat Med. 2003;31(3):195-200. doi:10.1515/ JPM.2003.026

8. Antepartum fetal surveillance. Practice Bulletin No. 145. American College of Obstetricians and Gynecologists. Obstet Gynecol. 2014;124: 182-192. doi:10.1097/01.AOG.0000451759.90082.7b

9. Lenstrup C, Haase N. Predictive value of antepartum fetal heart rate non-stress test in high-risk pregnancy. Acta Obstet Gynecol Scand. 1985;64(2):133-138. doi.org/10.3109/00016348509154706

10. Olofsson P, Sjöberg NO, Solum T. Fetal surveillance in diabetic pregnancy. I. Predictive value of the nonstress test. Acta Obstet Gynecol Scand. 1986;65(3):241-246. doi.org/10.3109/00016348609155178

11. Hoyer D, Żebrowski J, Cysarz D, et al. Monitoring fetal maturation: Objectives, techniques and indices of autonomic function. Physiol Meas. 2017;38(5):R61-R88. doi:10.1088/1361-6579/aa5fca

12. Grivell RM, Alfirevic Z, Gyte GML, Devane D. Antenatal cardiotocography for fetal assessment (review). Cochrane Database Syst Rev. 2015; (9):CD007863. doi:10.1002/14651858.CD007863.pub4

13. Kitagawa M, Akiyama Y, Omi H, Sago H, Natori M. Development and clinical application of a telemedicine support system in the field of perinatal patient management. J Obstet Gynaecol Res. 2000;26(6): 427-434. doi.org/10.1111/j.1447-0756.2000.tb01353.x

14. Monincx WM, Birnie E, Zondervan HA, Bleker OP, Bonsel GJ. Maternal health, antenatal and at 8 weeks after delivery, in-home versus inhospital fetal monitoring in high-risk pregnancies. Eur J Obstet Gynecol Reprod Biol. 2001;94(2):197-204. doi.org/10.1016/S0301-2115(00) 00351-1

15. Moore KH, Sill R. Domiciliary fetal monitoring in a district maternity unit. Aust N Z J Obstet Gynaecol. 1990;30(1):36-40. doi.org/10.1111/ j.1479-828X.1990.tb03193.x

16. Di Lieto A, Giani U, Campanile M, De Falco M, Scaramellino M, Papa R. Prenatal telemedicine: Clinical experience with conventional and computerised antepartum telecardiotocography. Eur J Obstet Gynecol Reprod Biol. 2002;103(2):114-118. doi.org/10.1016/ S0301-2115(02)00035-0

17. Di Lieto A, De Falco M, Campanile M, et al. Regional and international prenatal telemedicine network for computerized antepartum cardiotocography. Telemed J E Health. 2008;14(1):49-54. doi:10.1089/tmj. 2007.0021 
18. Wapner RJ, Cotton DB, Artal R, Librizzi RJ, Ross MG. A randomized multicenter trial assessing a home uterine activity monitoring device used in the absence of daily nursing contact. Am J Obstet Gynecol. 1995;172(3):1026-1034. doi.org/10.1016/0002-9378(95)90038-1

19. Corwin MJ, Mou SM, Sunderji SG, et al. Multicenter randomized clinical trial of home uterine activity monitoring: Pregnancy outcomes for all women randomized. Am J Obstet Gynecol. 1996;175(5):1281-1285. doi.org/10.1016/S0002-9378(96)70041-8

20. Morrison J, Bergauer NK, Jacques D, Coleman SK, Stanziano GJ. Telemedicine: Cost-effective management of high-risk pregnancy. Manag Care. 2001;10(11):42-46,48-49.

21. Kerner R, Yogev Y, Belkin A, Ben-Haroush A, Zeevi B, Hod M. Maternal self-administered fetal heart rate monitoring and transmission from home in high-risk pregnancies. Int J GynaecolObstet. 2004;84(1):33-39. doi.org/10.1016/S0020-7292(03)00331-X

22. Reece EA, Hagay Z, Garofalo J, Hobbins JC. A controlled trial of selfnonstress test versus assisted nonstress test in the evaluation of fetal well-being. Am J Obstet Gynecol. 1992;166(2):489-492. doi.org/ 10.1016/0002-9378(92)91654-S

23. Tapia-Conyer R, Lyford S, Saucedo R, et al. Improving perinatal care in the rural regions worldwide by wireless enabled antepartum fetal monitoring: A demonstration project. Int J Telemed Appl. 2015:794180. doi:10.1155/2015/794180

24. R Core Team. R: A language and environment for statistical computing. Vienna, Austria: R Foundation for Statistical Computing; 2018 https://www.R-project.org/. Accessed February 19, 2019.
25. Spilka J, Chudáček V, Janků P, et al. Analysis of obstetricians' decision making on CTG recordings. J Biomed Inform. 2014;51:72-79. doi:10. 1016/j.jbi.2014.04.010

26. Rei M, Tavares S, Pinto $P$, et al. Interobserver agreement in CTG interpretation using the $2015 \mathrm{FIGO}$ guidelines for intrapartum fetal monitoring. Eur J Obstet Gynecol Reprod Biol. 2016;205:27-31. doi:10.1016/j. ejogrb.2016.08.017

27. ANGELS 2016 Annual Report. University of Arkansas for Medical Sciences. Little Rock, AR: University of Arkansas for Medical Sciences. https://angels.uams.edu/wp-content/uploads/sites/81/2010/12/ 2016-Angels-annual-report-2-revised.pdf. Accessed February 19, 2019.

28. Rauf Z, O'Brien E, Stampalija T, Ilioniu FP, Lavender T, Alfirevic Z. Home labour induction with retrievable prostaglandin pessary and continuous telemetric trans-abdominal fetal ECG monitoring. PLoS One. 2011;6(11):e28129. doi:10.1371/journal.pone.0028129

29. Mills TA, Ricklesford C, Heazell AE, Cooke A, Lavender T. Marvelous to mediocre: Findings of national survey of UK practice and provision of care in pregnancies after stillbirth or neonatal death. BMC Pregnancy Childbirth. 2016;16:101. doi:10.1186/s12884-016-0891-2

30. Hollander JE, Davis TM, Doarn C, et al. Recommendations from the First National Academic Consortium of Telehealth. Popul Health Manag. 2018;21(4):271-277. doi:10.1089/pop.2017.0080 